\title{
Hepatitis A, B and $C$ viral co-infections among HIV-infected adults presenting for care and treatment at Muhimbili National Hospital in Dar es Salaam, Tanzania
}

\author{
Tumaini J Nagu*1, Muhammad Bakari ${ }^{1}$ and Mecky Matee ${ }^{2}$
}

Address: ${ }^{1}$ Department of Internal Medicine, School of Medicine, Muhimbili University of Health and Allied Sciences, P.O. Box 65001, Dar es Salaam, Tanzania and 2Department of Microbiology and Immunology, School of Medicine, Muhimbili University of Health and Allied Sciences, P.O. Box 65347, Dar es Salaam, Tanzania

Email: Tumaini J Nagu* - jtjoyce20@hotmail.com; Muhammad Bakari - mbakari@muhas.ac.tz; Mecky Matee - mmatee@muhas.ac.tz

* Corresponding author

Published: 19 December 2008

BMC Public Health 2008, 8:416 doi:10.1/86/147/-2458-8-416

This article is available from: http://www.biomedcentral.com/I47I-2458/8/4I6

(C) 2008 Nagu et al; licensee BioMed Central Ltd.

This is an Open Access article distributed under the terms of the Creative Commons Attribution License (http://creativecommons.org/licenses/by/2.0), which permits unrestricted use, distribution, and reproduction in any medium, provided the original work is properly cited.
Received: II August 2008

Accepted: 19 December 2008

\begin{abstract}
Background: Tanzania is currently scaling-up access to anti-retro viral therapy (ART) to reach as many eligible persons as possible. Hepatitis viral co-infections are known to influence progression, management as well as outcome of HIV infection. However, information is scarce regarding the prevalence and predictors of viral hepatitis co-infection among HIV-infected individuals presenting at the HIV care and treatment clinics in the country.
\end{abstract}

Methods: A cross-sectional study conducted between April and September 2006 enrolled 260 HIV-I infected, HAART naïve patients aged $\geq 18$ years presenting at the HIV care and treatment clinic (CTC) of the Muhimbili National Hospital (MNH). The evaluation included clinical assessment and determination of CD4+ T-lymphocyte count, serum transaminases and serology for Hepatitis $A, B$ and $C$ markers by ELISA.

Results: The prevalence of anti HAV IgM, HBsAg, anti-HBc IgM and anti-HCV IgG antibodies were $3.1 \%, 17.3 \%, 2.3 \%$ and $18.1 \%$, respectively. Dual co-infection with HBV and HCV occurred in 10 individuals (3.9\%), while that of HAV and HBV was detected in two subjects $(0.8 \%)$. None of the patients had all the three hepatitis viruses. Most patients (8I.1\%) with hepatitis co-infection neither had specific clinical features nor raised serum transaminases. History of blood transfusion and jaundice were independent predictors for $\mathrm{HBsAg}$ and anti-HBc lgM positivity, respectively.

Conclusion: There is high prevalence of markers for hepatitis B and C infections among HIV infected patients seeking care and treatment at $\mathrm{MNH}$. Clinical features and a raise in serum alanine aminotransferase were of limited predictive values for the viral co-infections. Efforts to scale up HAART should also address co-infections with Hepatitis $B$ and $C$ viruses.

\section{Background}

The National HIV/AIDS Care and Treatment Plan (NCTP) for Tanzania Mainland launched in 2004 was charged with the responsibility of providing quality human immunodeficiency virus (HIV) care and treatment services to as many HIV-infected residents of the United Republic of Tanzania as possible. The operational plan was to provide antiretroviral treatment to as many 
440,000 AIDS patients by the end of 2008; and to track the disease progression in some 1.2 million HIV-infected persons who were not clinically eligible for ART. The plan recommends that treatment be available through care and treatment clinics (CTC's) established over a five years time, at virtually all public and non-public hospitals down to the district level [1]. By December 2007, the numbers of health facilities providing HIV care and treatment was 210 . These provided non-ART care to estimated 118,286 clients and ART to 69,250 eligible patients [2].

Despite these achievements, relatively little is known regarding hepatitis viral co-infections among HIV infected patients enrolling at the CTC's. To the best of our knowledge, this is the first study to determine the prevalence and predictors of viral hepatitis co-infection among adults infected with HIV attending a CTC in Tanzania. Thus, findings obtained will provide valuable information for stakeholders within and outside Tanzania involved in scaling up care and treatment services.

\section{Methods}

\section{Study design and setting}

This was a hospital based descriptive cross-sectional study conducted at the Muhimbili National Hospital's (MNH) HIV care and treatment centre (CTC) between April 2006 and September 2006. MNH is a public and tertiary hospital located in Dar es Salaam, the largest commercial city of Tanzania.

\section{Study population}

Participants were the recently diagnosed HIV infected patients who were antiretroviral therapy (ART)-naïve, referred to the MNH-CTC from the various voluntary counselling and testing (VCT) centres in Dar es Salaam as well as the medical wards of MNH for initial work-up and possible initiation of treatment with antiretroviral therapy (ART).

\section{Interviews and clinical examination}

Interviews were conducted using a structured standard questionnaire to obtain information regarding demographic characteristics, history of jaundice, and symptoms of flu-like illness such as fever, nausea and vomiting; duration of illness, past medical history of blood transfusion, traditional uvulectomy, scarification, use of parenteral illicit/recreational drugs, as well as sexual, family and social histories. Clinical examination, conducted according to standard clinical examination methods [3], and the subsequent staging of patients using the WHO HIV staging criteria [4], followed the interviews.

\section{Laboratory investigations}

Specimens

Blood was collected aseptically into $10 \mathrm{ml}$ vacutainer tubes (BD, NJ USA) for biochemical, CD4+ count and viral serology tests. Biochemical and CD4+ T lymphocyte assays were performed within three hours of collection, while serum for serological assays of hepatitis A, B and C markers was stored at $-20^{\circ} \mathrm{C}$ until the time for assay.

\section{CD4+ T-Lymphocytes enumeration}

This was determined by flow cytometry using Becton Dickson Facs Calibur machine.

Alanine aminotransferase (ALAT) assay

The serum aminotransferase determined was alaninie aminotransferase (ALAT). The catalytic activity of ALAT (EC 2.6.1.2) was determined in serum using a COBAS MIRA chemistry analyzer (GMI, MI, USA) after it was calibrated.

Detection of anti HAV IgM, HBsAg, anti HbcAb lgM and Total anti HCV antibodies

The determination of anti hepatitis A virus antibody (anti HAV IgM), hepatitis B surface antigen (HBsAg), anti hepatitis B core IgM antibody (anti HbcAb-IgM), and anti hepatitis $\mathrm{C}$ virus IgG antibody (anti HCV) was done using the antibody capture ELISA (Adaltis - EIAgen kit). Samples that had reactivity to HCV were subjected to second ELISA (Abbott, USA), third-generation ELISA assay. Samples were considered to be positive for HCV if were reactive for both ELISAs.

\section{Data handling and statistical analysis}

Data was processed and analysed with SPSS version 12.0 [5]. The seroprevalence of HAV, HCV and HBV were expressed in percentages with their corresponding 95\% CIs. Pearson's Chi-Square $\left(\chi^{2}\right)$ was used to determine the association between the independent variables, however, where the numbers in a cell was less than 5, a Fisher's exact test was used instead. To approach normality, the baseline absolute CD4+ cell count data was log-transformed and Students' t-test was used to examine the association between the level of immunosuppression and presence of HAV, HBV and HCV infections. Multiple logistic regression was used to determine the independent predictors for each hepatitis and HIV co-infection. A pvalue $\leq 0.05$ was considered to be statistically significant.

\section{Ethical issues}

Ethical clearance was obtained from the research and publications committee of the Muhimbili University of Health and Allied Sciences (MUHAS). Study participants provided informed written consent prior to enrolment. Patients found with hepatitis co-infection were started on triple ART regimen that included lamivudine, with efa- 
virenz replacing nevirapine as a non-nucleoside anti-retroviral drug.

\section{Results}

Two hundred and sixty HIV infected patients were recruited during the study period, of whom $70.0 \%$ were females. Table 1 summarises the characteristics of the study population. The overall mean age was $37.3( \pm 9.5)$ years, ranging from 19 to 81 years. Males were significantly older, with a mean age of 41.4 years compared to females whose mean age was 35.6 years, $\mathrm{p}<0.0001$. The median CD4+ T-lymphocytes was 202 cells $/ \mu \mathrm{l}$.

The seroprevalence of HAV (anti HAV IgM), HBV(HBsAg), acute HBV(anti HBCAb) and HCV (anti HCV) were $3.1 \%$, $17.3 \%, 2.3 \%$ and $18.1 \%$, respectively (Table 2 ). Of the six patients with acute Hepatitis B infection (anti-HBc IgM antibody positive), two had occult HBV infection (anti $\mathrm{HBC}$ IgM positive but HBsAg negative), and the remaining four were positive for HBsAg. HBV carrier state, defined as being $\mathrm{HBsAg}$ positive and $\mathrm{HBC}$ IgM antibody negative, was present in 41 patients $(15.8 \%)$. The prevalence of any of the four hepatitis markers was found to be $34.6 \%$ (Table 2).
Co-infection with both HBV and HCV (HBsAg and HCV $\mathrm{Ab}$ ) occurred in 10 individuals (3.9\%) while that of HAV and HBV (anti HAV IgM and HBsAg) occurred in two subjects $(0.8 \%)$. None of the investigated patients was found to be co-infected with HAV and HCV. Similarly, none of the patients had all the three hepatitis viruses (HAV, HBV and HCV), (Table 2). There was neither an association between the occurrence of HBV and HCV nor between HAV and HBV.

The prevalence of HCV infection increased with age $\left(\chi_{\text {trend }}\right.$ $=4 ; \mathrm{p}=0.04)$, with the oldest age group $(50+$ years $)$ having the highest proportion (Table 3 ). The prevalence of HBV infection among males $(21.8 \%)$ was non-significantly higher than that among females (15.4\%). Similarly, widowed and divorced subjects had the highest prevalence (39.7\%) for HCV while currently married had the lowest prevalence of HCV (13.8\%). Subjects who were never married had the highest prevalence $(20.9 \%)$ of HBV infection. However, there was no statistically significant association between viral hepatitis infection and sex, marital status or education status (table 3). Furthermore, univariate analysis showed no association between the presence of any of the hepatitis viruses with blood trans-

Table I: Socio-demographic characteristics of the study population $(n=260)$

\begin{tabular}{|c|c|c|c|c|}
\hline Characteristic & $\begin{array}{l}\text { Male (\%) } \\
n=78\end{array}$ & $\begin{array}{l}\text { Female (\%) } \\
N=182\end{array}$ & $\begin{array}{l}\text { Total } \\
n=260\end{array}$ & P-value \\
\hline Age group & & & & $<0.01$ \\
\hline $18-29$ & $3(3.8)$ & $48(26.3)$ & $51(19.6)$ & \\
\hline $30-39$ & $38(48.7)$ & 87 (47.8) & $125(48.1)$ & \\
\hline $40-49$ & $28(35.9)$ & $31(17.0)$ & $59(22.7)$ & \\
\hline $50+$ & $9(11.5)$ & $16(8.8)$ & $25(9.6)$ & \\
\hline Marital Status & & & & 0.04 \\
\hline Single & $16(20.5)$ & $5 I(28.0)$ & $67(25.8)$ & \\
\hline Married & $47(60.3)$ & $83(45.6)$ & $130(50.0)$ & \\
\hline Divorced & $10(12.8)$ & $18(9.9)$ & $28(10.8)$ & \\
\hline Widowed & $5(6.4)$ & $30(16.5)$ & $35(13.5)$ & \\
\hline Education & & & & 0.04 \\
\hline Primary \& below & $44(56.4)$ & $125(68.7)$ & $169(65.0)$ & \\
\hline Secondary & $22(28.2)$ & $41(22.5)$ & $63(24.2)$ & \\
\hline Post Secondary & $12(15.4)$ & $16(8.8)$ & $28(10.8)$ & \\
\hline \multicolumn{5}{|c|}{ Baseline CD4+ count (cells/ $\mu \mathrm{l})$} \\
\hline$<200$ & $43(56.6)$ & $77(46.1)$ & $120(49.4)$ & \\
\hline $200-350$ & $19(25.0)$ & $27(16.2)$ & $46(18.9)$ & \\
\hline$>350$ & $14(18.4)$ & $63(37.7)$ & 77 (3I.7) & $<0.01$ \\
\hline WHO-HIV stage & & & & 0.66 \\
\hline I & $15(19.2)$ & $45(24.7)$ & $60(23.1)$ & \\
\hline II & $20(25.6)$ & $47(25.8)$ & $67(25.8)$ & \\
\hline III & $32(41.0)$ & $72(39.6)$ & $104(40.0)$ & \\
\hline IV & II (14.1) & $18(9.9)$ & $29(11.2)$ & \\
\hline
\end{tabular}


Table 2: Sero-prevalence of viral hepatitis markers among the study population $(n=260)$

\begin{tabular}{lcc}
\hline Marker & No (\%) & $\mathbf{9 5 \%} \mathbf{C l}$ \\
\hline HAV-IgM antibodies & $8(3.1)$ & $1.3-6.0$ \\
HBsAg & $45(17.3)$ & $12.9-22.5$ \\
HBc IgM antibodies & $6(2.3)$ & $0.9-5.0$ \\
HCV Ab & $47(18.1)$ & $13.6-23.3$ \\
HBsAg \& HBc IgM & $4(1.6)$ & $0.4-3.9$ \\
HBsAg \& HCV Ab & $10(3.9)$ & $1.9-7.0$ \\
& & \\
Any viral marker & $90(34.6)$ & $28.9-40.7$
\end{tabular}

fusion, illicit drug use, uvulectomy and traditional or cosmetic scarification.

Table 4 shows that out of all patients with HAV infection $50 \%$ had nausea and $37.5 \%$ had vomiting. These proportions were significantly higher than corresponding proportions among patients without HAV infection. Moreover, patients with acute HBV (HBcAb IgM) were more likely to have jaundice $(66.7 \%)$, hepatomegaly $(66.7 \%)$, raised alanine aminotransferase \{ALAT $(66.7 \%)$ or raised total bilirubin $(66.7 \%)$. However, when clinical features and biochemical markers were considered together, only 17 out of $90(18.9 \%)$ patients with any of the markers for hepatitis had jaundice (by history or examination), or hepatomegaly or elevated ALAT. Importantly, only $10.0 \%$ of the patients co-infected with hepatitis virus $\mathrm{A}, \mathrm{B}$ or $\mathrm{C}$ co-infection had abnormal serum ALAT.

Table 4 also shows that the mean CD4+ T-lymphocyte counts among patients co-infected with either HAV, or $\mathrm{HBV}$, or HCV were not significantly different from the mean values among patients without the corresponding hepatitis co-infection.

A set of variables was selected to search for predictors of the viral hepatitis infections including, age, sex, blood transfusion, scarification, nausea and vomiting, jaundice, palpable hepatomegaly and the presence of other viral hepatitis infection. Significant predictors of co-infection with the respective viral hepatitis are summarised in table 5. Presence of nausea, history of prior blood transfusion, and presence of jaundice were the independent predictors of HAV, HBV and acute HBV co-infections respectively.

\section{Discussion}

This study reveals a high burden of hepatitis viral co-infection among HIV infected, ART naïve patients who sought care at a tertiary public health facility in Tanzania, with more than a third of the study participants being coinfected.

Table 3: Sero-prevalence of viral hepatitis markers according to demographic characteristics $(n=260)$

\begin{tabular}{|c|c|c|c|c|c|}
\hline Characteristic & $\begin{array}{l}\text { Number tested } \\
\mathbf{N}\end{array}$ & $\begin{array}{l}\text { Anti HAV-IgM + } \\
\text { n (\%) }\end{array}$ & $\begin{array}{l}\text { HBsAg + } \\
\text { n (\%) }\end{array}$ & $\begin{array}{l}\text { Anti HCV + } \\
\text { n (\%) }\end{array}$ & $\begin{array}{l}\text { Any Hepatitis + } \\
\text { n (\%) }\end{array}$ \\
\hline \multicolumn{6}{|l|}{ Age } \\
\hline $18-29$ & 51 & I (2.0) & $12(23.5)$ & $7(13.7)$ & $16(31.4)$ \\
\hline $30-39$ & 125 & $3(2.4)$ & $16(12.8)$ & $22(17.6)$ & $38(30.4)$ \\
\hline $40-49$ & 59 & $3(5.1)$ & $15(25.4)$ & $9(15.3)$ & $25(42.4)$ \\
\hline $50+$ & 25 & I (4.0) & $2(8.0)$ & $9(36.0)$ & II (44.0) \\
\hline P*-value & & $* *$ & 0.06 & 0.09 & 0.28 \\
\hline \multicolumn{6}{|l|}{ Sex } \\
\hline Male & 78 & $\mathrm{I}(\mathrm{I} .3)$ & $17(2 \mid .8)$ & $10(12.8)$ & $27(34.6)$ \\
\hline Female & 182 & $7(3.8)$ & $28(15.4)$ & $37(20.3)$ & $63(34.6)$ \\
\hline $\mathrm{P}^{*}$ value & & $0.442 *$ & 0.211 & 0.149 & I \\
\hline \multicolumn{6}{|l|}{ Education } \\
\hline Primary \& Below & 169 & $4(2.4)$ & $29(17.2)$ & $35(20.7)$ & $62(36.7)$ \\
\hline Secondary \& Above & 91 & $4(4.4)$ & $16(17.6)$ & $12(13.2)$ & $28(30.8)$ \\
\hline $\mathrm{P} *$ value & & $0.456 *$ & 0.932 & 0.133 & 0.339 \\
\hline \multicolumn{6}{|l|}{ Marital status } \\
\hline Never Married & 67 & $2(3.0)$ & $14(20.9)$ & $12(17.9)$ & $24(35.8)$ \\
\hline Currently Married & 130 & $5(3.8)$ & $23(17.7)$ & $18(13.8)$ & $4 I(31.5)$ \\
\hline Divorced/Widowed & 63 & $\mathrm{I}(1.6)$ & $8(12.7)$ & $17(27.0)$ & $25(39.7)$ \\
\hline $\mathrm{P}^{*}$ value & & $* *$ & 0.460 & 0.084 & 0.522 \\
\hline
\end{tabular}

I. Key: $*$ = fishers' exact test $* *=$ no test done due to small numbers. "Any hepatitis" = positivity of any of the viral markers tested antibodies

2. $\mathbf{P *}$ value compares the proportion on each marker by various sociodemographic categories 
Table 4: Clinical characteristics of patients with viral hepatitis markers $(n=260)$

\begin{tabular}{|c|c|c|c|c|}
\hline & HAV-IgM +ve & HbsAg +ve & HBclgM +ve & HCV-ab +ve \\
\hline \multicolumn{5}{|l|}{ Clinical feature, $\mathbf{n}(\%)$} \\
\hline Fever & $3(37.5)$ & $17(37.8)$ & $2(33.3)$ & $18(38.3)$ \\
\hline Nausea & $4(50.0)^{*}$ & $5(11.1)$ & I (16.7) & $7(14.9)$ \\
\hline Vomiting & $3(37.5)^{*}$ & $6(13.3)$ & I (16.7) & $4(8.5)$ \\
\hline Jaundice & 0 & $5(I I .1)$ & $4(66.7)^{*}$ & $4(8.5)$ \\
\hline Hepatomegaly & 0 & $5(11.1)$ & $4(66.7)^{*}$ & $3(6.4)$ \\
\hline \multicolumn{5}{|c|}{ Biochemical characteristics, n (\%) } \\
\hline Elevated ALAT & $\mathrm{I}(12.5)$ & $4(8.9)$ & $2(33.3)^{*}$ & $2(4.3)$ \\
\hline Elevated Total bilirubin & 0 & $5(11.1)$ & $4(66.7)^{*}$ & $5(10.6)$ \\
\hline \multicolumn{5}{|c|}{ Immunological characteristic } \\
\hline Mean CD4+ T-cells (cells/ $\mu l)$ & 113 & 198 & 134 & 222 \\
\hline
\end{tabular}

$*=\mathrm{P}<0.05$, when compared with those having no corresponding marker

HCV was the most prevalent infection (18.1\%) which is in keeping with the findings of Telatela et al [6] who documented HCV sero-prevalence of $13.8 \%$ among HIV infected children in the same institution [6]. This prevalence is higher than that reported among among blood donors at the same hospital [7-9] probably due to the fact that all our subjects were HIV-infected and that HCV has similar transmission modes as HIV. The lower prevalence of HCV reported by Wadell et al. [8] could also be due to the fact that they used an HCV RNA assay, which is a more stringent assay [10]. The increase in the prevalence of HCV infection with age that was observed is a reflection of a cumulative risk with time [11].

We found a higher prevalence of HBsAg (17.3\%) compared to a study conducted among blood donors $(8.8 \%-$ $11.0 \%)$ at the same setting $[7,9]$. Three main reasons are postulated; firstly, the shared modes of transmission between HIV and HBV [12]. Secondly, is the known phenomenon of reactivation of HBV in the setting of HIV immunodeficiency [13] and lastly, the higher rates of childhood horizontal HBV transmission in sub-Saharan Africa [14]. It is important to note two subjects with anti HBC IgM antibodies but negative HBsAg who may have had occult HBV viremia as demonstrated previously in HIV subjects [15]. Notably occult HBV infection is likely

Table 5: Likelihood of viral hepatitis co-infection using clinical features presented as odds ratios (OR) with $95 \%$ confidence intervals $(\mathrm{Cl})(\mathrm{n}=243)$ *

\begin{tabular}{lllc}
\hline Outcome & Predictor & OR $(\mathbf{9 5} \% \mathbf{C l})$ & p-value \\
\hline $\mathrm{HAV}$ & Nausea & $4.18(1.46-11.96)$ & $<\mathbf{0 . 0 1}$ \\
$\mathrm{HBsAg}$ & Blood transfusion & $2.59(1.09-6.15)$ & $\mathbf{0 . 0 3}$ \\
$\mathrm{HBcAb}$ & Jaundice & $41.07(6.78-248.89)$ & $<\mathbf{0 . 0 1}$
\end{tabular}

*CD 4+ T lymphocyte counts for 17 patients were lost and could not be traced. to be missed diagnosis when HBsAg is employed as a routine screening test, which may consequently lead to silent liver damage.

The prevalence of HAV-IgM (3.1\%) reported in this study is much lower than that of $41.0 \%$ found in a Kenyan study [16]. The difference is most probably due to the fact that the latter study investigated patients who already had clinical hepatitis as evidenced by jaundice.

About $4 \%$ of our study population had dual HBV/HCV infection evidenced by co-existence of HBsAg and anti$\mathrm{HCV}$ total antibodies. However, the occurrence of the two viruses (HBV and HCV) was not significantly associated, corroborating the findings of previous studies done in the country $[6,7]$.

In this study, the association of hepatitis viral co-infection with serum alanine aminotransferase (ALAT) as well as clinical features was very limited. Only $10 \%$ of HIV/hepatitis co-infected patients had elevated ALAT and clinical features suggestive of acute liver disease were insignificantly associated with hepatitis co-infection. The asymptomatic pattern of co-infection in our study population would probably be due to the fact that we detected less subjects with acute hepatitis (HAV-IgM 3.1\%, HBsAg $2.3 \%$ ) compared to those with chronic HBV and HCV coinfection. The paucity of signs and symptoms of liver damage has been documented in HIV patients with chronic viral hepatitis co-infection $[17,18]$ and has been attributed to decreased hepatocellular injury associated with the HIV-induced immunodeficiency [19].

In this study, except for the association between age and $\mathrm{HCV}$ infection, demographic characteristics were not associated with the occurrence of any of the investigated hepatitis infections. Our results show that HCV co-infection 
was associated with increasing age, which may reflect a cumulative risk over time as previously reported by Kondili [11]. Notably, we observed no statistically significant association between the occurrence of the either HBsAg or HCV and sex and marital status, which is in keeping with other studies conducted in the country [20].

In this study there was no association between absolute CD4+ T-lymphocyte count and the presence of hepatitis co-infection. Indeed the association between hepatitis viral co-infection and CD4+ T lymphocytes count is currently a subject of debate, with some studies showing no existence of a relationship [21] and others showing the association [22]. The lack of association is probably due to the impaired qualitative response to hepatitis virus in HIV infection rather than impairment in the absolute numbers of CD4+ T-lymphocytes [23]. However, the lack of association in our study could also be due to that fact that most of our study patients had low CD4 counts, (median $<202$ cells $/ \mathrm{mm}^{3}$ ) at baseline.

Evidently from this study is the fact that most (> 80\%) of the patients with hepatitis viral co-infection, presented with no specific liver damage-related signs and biochemical changes, emphasizing the need for routine screening of viral markers in HIV patients. This is currently not part of the Tanzanian HIV care and treatment guidelines [24]. Secondly, there are implications for the choice of an appropriate regimen for the hepatitis co-infected patients that should include two active anti HBV agents to avoid viral mutations and thus enhance outcome [25,26]. The, current first line ART regimen in Tanzania (stavudine, lamivudine and nevirapine or efavirenz) [24] does not sufficiently cover for HBV [25]. Moreover, a prolonged use lamivudine against HIV infection in undiagnosed viral hepatitis infection may result in resistant HBV mutants [27]. Flexibility in the regimen under such circumstances to include appropriate drugs to take care of $\mathrm{HBV}$ or $\mathrm{HCV}$ co-infections should be considered. In addition, it is likely that the undiagnosed cases of hepatitis co-infected patients may be kept on nevirapine based ART combinations leading to nevirapine hepatotoxicity [28], and thus defeating the national objective of improving the quality of life of these patients [24]. Finally, patients with HIV/ Hepatitis co-infection may complicate ART with an immune reconstitution syndrome (IRIS), which may be confused with drug toxicity or acute hepatitis infection. It is therefore important for health care workers to be cognisant of these facts to improve the care of patients infected with HIV

\section{Conclusion}

HBV and HCV infections are relatively common among Tanzanian HIV patients and should be considered during baseline work-up of HIV patients in order to provide appropriate ART. The limited predictive value of clinical features and biochemical markers indicate that care and treatment centers should be equipped with laboratory facilities to diagnose hepatitis viral co-infection. Scaling up of ART services in the country should go hand in hand with reviewing HIV treatment guidelines to cater for $\mathrm{HBV} /$ HCV co-infection.

\section{Competing interests}

The authors declare that they have no competing interests.

\section{Authors' contributions}

TJN designed the study, conducted the interviews and clinical examinations. $\mathrm{MB}$ assisted study design and supervised interviews and clinical examination. MIM assisted study design and supervised laboratory work. Finally, all authors participated in the preparation of the manuscript, read and approved the final manuscript.

\section{Acknowledgements}

The authors would like to acknowledge the technical support provided by the members of the departments of Internal medicine and Microbiology of Muhimbili University of Health and Allied Sciences (MUHAS). We thank Ms Betty Mchaki who performed the laboratory work. We are grateful to the administration Muhimbili National Hospital (MNH), National Institute for Medical Research (NIMR) and Tanzania Commission for AIDS (TACAIDS) for funding this research work. Finally, we appreciate the participation of our patients without whom this study would have not been possible.

\section{References}

I. United Republic of Tanzania. Ministry of Health: Report of the 3 by 5 Mission to Tanzania on Scaling up Antiretroviral Treatment as Part of the Global Emergency Response to HIVI AIDS.

2. United Republic of Tanzania. Ministry of Health: National AIDS control program (NACP). Annual report, Tanzania 2007.

3. Swash M: Hutchison's clinical methods London Royal Hospital, Saunders Press; 1995.

4. World Health Organization: Treat 3 million by 2005. Interim WHO clinical staging of HIVIAIDS and HIVIAIDS case definitions for surveillance. African region. WHO/HIV/2005.02. [http://www.who.int/hiv/pub/guidelines/clinicalstaging.pdf].

5. SPSS Inc version 10.0: The statistical Package for the Social Sciences Chicago, II: SPSS Inc; 2004.

6. Telatela SP, Mecky MI, Munubhi EK: Seroprevalence of hepatitis $B$ and $C$ viral co-infections among children infected with human immunodeficiency virus attending the paediatric HIV care and treatment center at Muhimbili National Hospital in Dar-es-Salaam, Tanzania. BMC Public Health 2007, 7:338.

7. Matee MI, Magesa PM, Lyamuya EF: Seroprevalence of Human Immunodeficiency Virus, Hepatitis $B$ and $C$ Viruses and Syphilis Infections among Blood Donors at the Muhimbili National Hospital in Dar Es Salaam, Tanzania. BMC Public Health 2006, 6:21.

8. Waddell RD, Magesa PM, Pallangyo KJ, Matee MI: Co-infection with HIV and HCV in Blood bank population in Dar es Salaam Tanzania. J Clin Virol 2006, 36(3):237-238.

9. Matee MI, Lyamuya EF, Magesa PM, Mbena EC: Prevalence of transfusion-associated viral infections and syphilis among blood donors in Muhimbili Medical Centre in Dar es Salaam, Tanzania. East Afr Med J 1999, 76:167-171.

10. Hollander $H$, Wright $T$, Held M: Hepatitis C serology and viremia in HIV-infected men. Int Conf AIDS 9:358.

11. Kondili LA, Chione P, Constantino A: Infection rate and spontaneous seroreversion of anti-hepatitis $C$ virus infection in the general population. Gut 2002, 50:693-696. 
12. Fainboim H, Gonzalez J, Fassio : Prevalence of hepatitis viruses in an anti-human immunodeficiency virus-positive population from Argentina - A multicentre study. J Viral Hepat 1999, 6(I):53-57.

13. Barin F, Baty G, Bastides F, Dubois F, Besnier JM, Choutet P, Goudeau $A$ : Incidence of hepatitis $B$ virus reactivation in $\mathrm{HIV}-\mathrm{I}$ infected patients. Antivir Ther 2003, 8(I):.

14. Tabor E, Bayley AC, Cairns L, Gerety RL: Horizontal transmission of hepatitis $B$ virus among children and adults in five rural villages in Zambia. J Med Virol I985, I 5: I I3-I 20.

I5. Mphahlele MJ, Lukhwareni A, Burnett RJ, Moropeng LM, Ngobeni JM: High risk of occult hepatitis B virus infection in HIV-positive patients from South Africa. J Clin Virol 2006, 35(I): I4-20.

16. Atina JO, Ogutu O, Hardison : Prevalence of hepatitis A, B, C and human immunodeficiency virus seropositivity among patients with acute icteric hepatitis at the Kenyatta National Hospital, Nairobi. East Afr Med J 2004, 8 I(4): I 83-I87.

17. Horvath J, Raffanti SP: Clinical aspects of the interactions between human immunodeficiency virus and the hepatotropic viruses. Clin Infect Dis 1994, I 8:339-347.

18. Zhang $\mathrm{YH}, \mathrm{Chen} X \mathrm{Y}$, Jiang $\mathrm{Y}$ : Analysis of causes for liver function deterioration in patients with HIV/HCV co-infection. Hepatobiliary Pancreat Dis Int 2004, 3(4):538-542.

19. Krogsgaard K, Lindhardt BO, Nielson JO: The influence of HTLVIII infection on the natural history of hepatitis $B$ virus infection in male homosexual HBsAg carriers. Hepatol 1987, 7:37-4I.

20. Plellzzer G, Ble C, Zamperetti N: Serological survey of Hepatitis B infection in Tanzania. Public Health I994, 108(6):427-43।.

21. Sulkowski MS, Moore RD, Mehta SH: Hepatitis $\mathbf{C}$ and Progression of HIV disease. JAMA 2002, 288(2):24I-243.

22. Otedo AE: HBV, HIV co-infection at Kisumu District Hospital, Kenya. East Afr Med J 2004, 8 I (I 2):626-630.

23. Harcourt G, Gomperts E, Donfield S, Klenerman P: Diminished frequency of Hepatitis $\mathbf{C}$ virus specific interferon $\gamma$ secreting CD4+ $T$ cells in Human immunodeficiency virus co-infected patients. Gut 2006, 55:|484-|487.

24. The United Republic of Tanzania. Ministry of Health. National AIDS Control Program: National Guidelines for the Clinical Management of HIV and AIDS. 2nd edition. 2005.

25. Cooper D, Dore G, Pozniak AL: Tenofovir Disoproxil Fumarate and Lamivudine Combination Therapy Compared to Lamivudine Alone for HBV in Therapy-naive HIV/HBV Coinfected Patients: 48-week Interim Results. IOth Conf Retrovir Oppor Infect 2003, 10:10-14.

26. Alberti A, Clumeck N, Collins S, Gerlich W, Lundgren J, Palu' G, Reiss $P$, Thiebaut R, Weiland O, Yazdanpanah Y, Zeuzem S: Short statement of the first european consensus Conference on the treatment of chronic Hepatitis B and C in HIV co-infected patients. Hepatol 2005, 42:6I5-624.

27. Cooley L, Bartholomeusz A, Ayres A: Hepatitis B Virus and HIV Co-Infection: Development of Lamivudine Resistance. 9th Conf Retrovir Oppor Infect 2002:24-28.

28. João E, Calvet G, Menezes J: Nevirapine toxicity in a cohort of HIV-I infected pregnant women. Am J Obstet Gynecol 2006, 194:199-202.

\section{Pre-publication history}

The pre-publication history for this paper can be accessed here:

http://www.biomedcentral.com/1471-2458/8/416/pre pub

\section{Publish with Bio Med Central and every scientist can read your work free of charge}

"BioMed Central will be the most significant development for disseminating the results of biomedical research in our lifetime. "

Sir Paul Nurse, Cancer Research UK

Your research papers will be:

- available free of charge to the entire biomedical community

- peer reviewed and published immediately upon acceptance

- cited in PubMed and archived on PubMed Central

- yours - you keep the copyright

Submit your manuscript here:

http://www.biomedcentral.com/info/publishing_adv.asp
BioMedcentral 